\title{
Rural Customer Satisfaction on E- Banking Services
}

\author{
J. Kannan, D. Venkatrama Raju
}

\begin{abstract}
Data Systems (IS) execution in advanced education is an enormous venture. Such ventures are relied upon to bring expanded productivity and adequacy, just as better quality administrations to partners. Our writing search didn't discover understudy data the board frameworks (SIMS) in Ethiopia or comparative low-salary nations. This exploration is work in progress. It endeavors to connect the writing hole for usage and achievement elements of SIMS in a college setting of low pay nations. The investigation will address the exploration question: what determinant components add to the achievement or disappointment of IS in advanced education establishments in Ethiopia, with specific reference to SIMS? The examination utilizes DeLone and McLean(1992, 2003) IS Success Model to recognize the components of IS achievement when applied to SIMS. We likewise examine two new builds top administration backing and client bolster that were discovered pertinent in the investigation setting.
\end{abstract}

Keywords : Student information management system, higher education institutions, IS Success Model, information quality, systemquality, user support, top management support.

\section{INTRODUCTION}

Information system is defined as a 'collection of subsystems defined by functional or organizational boundaries (Iivari,1991). It supports decision-making and control in organizations (Lucas, 1981) by utilizing information technology to capture, transmit, store, retrieve, manipulate, or display information used in one or more business processes' (Alter, 1996).Like any modern business sector, Higher Education Institutions (abbreviated as HEIs) need to achieve and enhance quality inits functioning. But these institutions face challenges in the process of attaining the objective of becoming better quality HEI.McClea and Yen, (2005) stated that:"In this sector the challenge begins with the institution's admission department. The admissions department functions as the delivery point for quality inputs, which should eventually become even higher quality outputs. The department, then, must collect significant amounts of data about students as well as maintain the ability to effectively analyze and transform the data into pertinent information. This develops a new function for the admission

Revised Manuscript Received on December 11, 2019.

J. Kannan, Department of Commerce and Economics, Bharath Institute of Higher Education and Research, Chennai, India. Email: sjkannan1986@gmail.com

D. Venkatrama Raju, Department of Commerce and Economics, Bharath Institute of Higher Education and Research, Chennai , India. Email: prof.dvraju@gmail.com department to perform - information technology[1]-[3]. Information technology presently represents a critical success factor for numerous organizations. Higher educational institutions fall into this category and have sought the status of first movers in relation to the development and implementation of information technology throughout the areas of academia" (McClea and Yen, 2005).

The above points signify that information system has become an important part of the institution of higher education and one of the major areas where information systems plays a key role is the Admissions Department. SIMS is a software application for educational establishments to manage student data that includes student admission information, course information, information on academic grades and other student-related data. The business practices and processes, and the information that guides decision making in large areas of the academy, interact with and derive from these information systems (Suwardi,2007). Its implementation is one of the largest investments (Suwardi, 2007) in higher education institutions[4]-[6]. The benefits of information technology in higher education admissions derive from the essential need to increase efficiency, boost productivity, and decrease costs while increasing applications and improving the quality of students accepted into educational programs (McClea and Yen, 2005).

Collecting, analyzing and transforming a growing student related data into pertinent information is difficult without the development and implementation of ICT-supported IS. Therefore, Universities and Colleges are currently investing on the development and implementation of SIMS to meet the requirements. Such investment on information systems is expected to bring increased efficiency and effectiveness as well as better quality services to the customers in the area. Therefore, the measurement of information systems success or effectiveness is critical to our understanding of the value and efficacy of IS management actions and IS investments (DeLone and McLean, 2003). In this regard, there should be research to identify factors that contribute to the success or failure of SIMS in HEIs in Ethiopia and other developing countries[7]-[9]. 
This research aims to make a contribution in addressing information system success factors for implementing and utilizing Information System in general, and SIMS in particular in Ethiopian university system from a national perspective, an area in which our search of the literature yielded little evidence of research activities. As it is stated by Anakwe, et al. (1999) many studies on IS implementation success have been undertaken but few have concentrated on Least Developed Countries(LDCs). They also added that "there is growing concern that implementation and utilization of IS are being undertaken with in sufficient consideration of economic, social and political difficulties. Identifying the determinants for IS success with in these differing settings is important in LDCs. This research project will therefore attempt to bridge the gap in the literature between the Information System utilization and IS success factors for its use in a university context of low income countries such as Ethiopia[10].

IS in higher education institutions of Ethiopia with particular reference to SIMS? The study uses DeLone and McLean model to identify the dimensions of IS success when applied to SIMS in the context of aHEIs. In addition to the sex constructs of the original model, i.e., information quality, system quality, use, user satisfaction, individual impact, organizational impact; user support and top management support are considered to be relevant to the study area and added as moderating factors. Testing whether information systems success models like DeLone and MacLean's can be extended to investigate SIMS's success within a low income country context is the interest of the study.

The paper is organized in four sections. The first section develops the basis for the case study by introducing St. Mary'sUniversity College and its SIMS. The second section deals with the theoretical framework to be used in investigating the success or failure of SIMS. This section will present the DeLone and McLean (1992) information system success model, additional constructs to be added in the model which are determinant factors for the IS success in our context, definition of each construct and the hypothesis set for each of the constructs[11]-[13]. The third section presents the methodology to be followed in studying the IS success factors. In this section the method to be applied, measurement instruments, and sample size as well as data collection techniques will be discussed. In the last section we present our concluding remarks and indicate the expected results and contributions of the study.

\section{A. Conceptual Model}

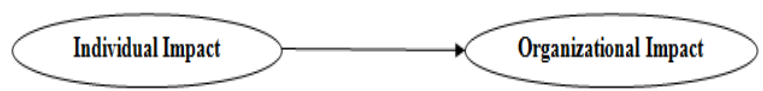

Interest in the territory of SIMS is a high need on account of Ethiopian HEIs. This is for the most part a result of the ongoing pattern of extension of HEIs and increment in understudy enlistment. As of late as the year 2005, there were just 9 open HEIs in Ethiopia. In the last three to four years 13 new state funded colleges were constructed and made operational, raising the number ofpublic HEIs to 22. Notwithstanding this around 250 private advanced education organizations have been built up in the previous ten years, the vast majority of which offer confirmation and declaration programs. Around 55 of the 250 private advanced education foundations offer degree projects and 2 of the 250 offer post graduate projects. Along these lines, an aggregate of 263 new open and private advanced education foundations have been built up in the previous ten years. This expanded the all out number of both open and private

HEIs to 272. Somewhat in view of this extension, the normal multi year development in tertiary level enlistment arrived at $27 \%$. This development got critical increment understudy enlistment. So as to adapt up to such extensions in understudy enlistment, foundations of advanced education are making interest in the improvement and execution of IS and it is a latest wonder on account of Ethiopia. Suitable assessment of these frameworks stays a significant plan for advanced education the board on the off chance that they are to see a decent return for their exorbitant speculation. Accordingly, our inspiration is to lead this examination to help recognize determinant factors that add to the achievement or disappointment of IS execution and use in HEIs with specific reference to SIMS in Ethiopia utilizing a particular case. We chose St. Mary's University College principally in view of the encounters one of the co-creators as a staff part at the college school during its framework improvement and usage. At present the analyst is additionally an essential client of the framework.

St. Mary's University College is a private HEI which was set up in the year 2000. It is one of the two private advanced education organizations that offer post graduate projects. It additionally offers degree, recognition and testament programs in customary mode (Regular and Extension eye to eye classes) just as in separation training mode. There are an absolute of 22 divisions in both traditional and separation instruction mode that offer degree, recognition and declaration programs. The total number of understudies in the two modes is 40,393, of which 16,833 are qualification understudies, with 20,545 confirmation understudies and3,015 Certificate understudies in both traditional and separation programs. The complete number of full time scholastic staff is 206, and that of regulatory staff is 778.SIMS for the University College is created in-house dependent on the necessity detail of the Registrar's Office. 
The framework is created utilizing PHP programming language with MySQL database. Apache Server is utilized to arrange the system. After appropriately testing the SIMS it was executed effectively in September 2008. The framework supports capacities including putting away and preparing understudies' confirmation information, taking care obviously enlistment, planning classes, entering and handling grades, producing evaluation reports and transcripts, preparing graduation related information and creating factual reports of various kind for different purposes[11].

SIMS connects with an autonomous Exam Correction Software to consequently refresh its database with new increments and changes obviously title, course code, and understudy information. It additionally consequently imports grades from the Exam Correction Software. SIMS likewise cooperates with other three bundles. One bundle is programming that is utilized by 16 Coordination Centers of Distance Education at various locales to process and advance consequences of ventures and research papers electronically to the fundamental Registrar Office. SIMS naturally imports the outcomes from the framework. The other bundle is Exam Attendance Information System which is utilized by Exam Unit of Distance Education and Departments to fuse and track understudy participation on test for the courses enlisted. SIMS additionally connects with this framework to consequently import test participation data. There is likewise fund programming which is known as PayCol. SIMS naturally encourages understudies' information to Pay Colsystem.

Clients of the framework incorporate all staff individuals from Registrar Office, account office just as the school personnel in various offices. The all out number of clients of the framework is around 292. The all out number of understudies bolstered by the framework, a sit is expressed above, is 40,393. The framework has been being used for as long as two and half years. At the underlying phase of execution here was information confound issue (counting understudy information and course related information) experienced during information relocation from the old framework to the enhanced one. It took a few months to take care of this issue. There is no other serious issue experienced with the exception of the minor ones which were redressed rather effortlessly[12].

\section{THEORETICAL FRAMEWORK}

\section{A. Background on the Model}

Research in the course of recent decades has brought about various ways to deal with the assessment of IS achievement. Some of the minclude framework use, Information Value, client fulfillment and all the more as of late help quality. Such differed ways to deal with IS success measures recommend absence of understanding in regards to the topic of what establishes IS achievement. One of the commonly cited papers in the writing is that of De Lone and McLean (1992).
In their paper, the creators blended 100 observational IS success measures (distributed somewhere in the range of 1981 and 1987) and proposed a model that joins a few individual dimensions of accomplishment into a general model of IS achievement. De Lone and McLean presented six significant measurements or classifications of IS success - framework quality, data quality, use, client fulfillment, singular effect and hierarchical impact. According to DeLone and McLean (2003), in the IS Success Model, "frameworks quality" measures specialized success;"information quality" measures semantic achievement; and "use, client fulfillment, singular effects," and "organizational impacts" measure viability achievement. As they have explained, an is first made, containing different highlights, which can be described as showing different degrees of framework and data quality. Next, clients and supervisors experience these includes by utilizing the framework and are either fulfilled or disappointed with the framework or its data items. The use of the framework and its data items at that point effects or impacts the individual client in the direct of their work, and these individual effects on the whole outcome in authoritative effects. As per Gable et al. (2003), the constructs/proportions of the Delone and McLean model gave a comprehensive see over the association - from a top management point of view, to that of information section officials' - and gave a nitty gritty arrangement of progress measurements[13]-[15].

As it is expressed in the presentation DeLone and McLean Information System Success Model is utilized as a hypothetical framework for the examination. This is for the most part on the grounds that the DeLone and McLean system is generally acknowledged as one of the more complete IS evaluation structures and has been utilized widely in experimental research (Ballantine et al., 1996). The model additionally enables us to assess the achievement of IS at various levels framework, individual and hierarchical.

\section{B. Construct Definition and Hypothesis}

Framework quality is a proportion of the data preparing framework itself. Most measures in this classification tap engineering oriented performance qualities. It comprises of execution attributes of the frameworks which incorporate resource utilization, dependability, reaction time, simplicity of terminal use, information precision, unwavering quality, culmination, framework adaptability and ease of use. In the instance of Student Information Management System, convenience, reaction time, correspondence without hardly lifting a finger of learning are the significant characteristics that are esteemed by clients of the Student Information Management System. Seddon and Kiew (1994) found in their way examination that data quality and framework quality are significant determinants of in general client fulfillment. 
The Technology Acceptance Model (Davis et al., 1989) predicts that apparent straightforwardness

of utilization, as a part of framework quality (DeLone and McLean, 1992) is a critical immediate and backhanded determinant of utilization, the indirect impact being directed through apparent value. It is normal thusly, that the higher the framework quality, the better the accomplishment of Student Information Management System (SIMS) as far as improved use and client fulfillment. This is spoken to by the accompanying speculation.

H1a: SIMS quality will be emphatically identified with the utilization of SIMS.

H1b: SIMS quality will be emphatically identified with SIMS client fulfillment.

Data quality speaks to proportions of data frameworks yield. It is an element of the estimation of the yield delivered bya framework as saw by the client. Average measures around there incorporate exactness, accuracy, cash, yield timeliness, reliability, fulfillment, succinctness, arrangement and significance (Bailey and Pearson, 1983). Different creators likewise included understandability, report handiness, adequacy, opportunity from predisposition, equivalence, and quantitativeness. In this examination, data quality is considered as having attributes of exactness, yield practicality, fulfillment, output clarity and arrangement. The framework ought to have the option to give point by point data about the understudy including, affirmation status, academic status, all out courses taken and staying, all out terms visited and remaining, and grade lacks. Clients should confirm that the data gave is exact, auspicious gave, dependable, complete, and showed in fitting configuration. A positive conformance of these qualities by the clients suggests that there is adequacy in the utilization of SIMS. Seddon andKiew (1994) additionally expressed that data quality is a huge determinant of in general client fulfillment. This prompts the following theory.

H2a: SIMS data quality will be emphatically identified with SIMS use.

H2b: SIMS data quality will be emphatically identified with SIMS client fulfillment[16].

Top the board backing is conceptualized as the association and investment of the official or top level the executives of the association in IT/IS exercises (Jarvenpaa and Ives, 1991, refered to in Hussien, et al., 2007). As it is expressed previously, there are a number of concentrates that approved the positive connection between top administration support and IS achievement. Ruler and Teo, (1996) discovered top administration bolster encouraged the effective organization

of key IS applications, while absence of top management bolster was found to restrain its vital utilization/IS. Igbaria et al., (1997) tried an auxiliary condition model on individualized computing factors in little firms and discovered administration bolster has positive direct impacts on perceive dusefulness and saw usability. Ang et al., (2001) analyzed 47 Malaysian open part offices on IT utilization to help complete quality the board (TQM). In this examination top administration support for IT applications is seen as the highest predictor of IT utilization. Every one of these discoveries demonstrated that top the executives backing has huge effect on IS achievement. All these discoveries empower us to create theory 3 which is expressed as follows.H3: The impact of framework quality and data quality on SIMS use and client fulfillment is the positive function of top administration support.

Client backing is for the most part worried about the specialized help and help given to clients as far as working the information systems in the association (Hussein, et al., 2005). As it is expressed above there are numerous investigations led in the zone which confirmed solid connection between client backing and accomplishment in client figuring. In a robotized situation where there is ICT based Student Information Management System we accept that specialized help to clients of the frameworks is significant.

Clients will in all likelihood look for help in utilizing the frameworks in their day by day activities. In view of the confirmations, it is conceivable to hypothesize the connection between client support and IS accomplishment as pursues:

H4: The impact of framework quality and data quality on SIMS use and client fulfillment is the positive function of client support. Use alludes to the beneficiary utilization of the yield of a data framework. A portion of the attributes used to measure information use by various creators include: measure of utilization/length of utilization, number of request, number of capacities used, number of records got to, recurrence of access, number of reports produced, consistency of utilization, use for proposed purpose, purpose of utilization and inspiration to utilize. In our setting "Use" measures everything including information passage, information control (edit,delete), grade report and transcript age, factual report age, recovering and any understudy related data and giving it to an outsider. For this situation, use isn't intentional. In this manner, for this investigation use for proposed reason, degree of useand number of framework's capacities utilized are viewed as the most appropriate. Dissonance hypothesis by Fish bein and Ajzen (1975, refered to in DeLone and McLean, 1992), recommends that IS use prompts user satisfaction. The discoveries of met a analysis led by Bokhari (2005) lead to the decision that there exists a "medium" and huge positive connection between framework use and client fulfillment (i.e. $\mathrm{r}=0.2555)$.

Published By:

Blue Eyes Intelligence Engineering 
Notwithstanding these, SIMS use is an immediate precursor of individual effect factors. In this way, considering these connections the accompanying hypothesis can be made for SIMS use[17]-[19].

H5a: SIMS utilize has positive association with and prompts client fulfillment $\mathrm{H}$ 6: SIMS use will be decidedly related to individual effects of the SIMS. User fulfillment can be characterized as the degree of which clients accept the data framework accessible to them meets their information and framework prerequisites (Baroudi et al., 1983). Client fulfillment is a regularly utilized proportion of framework achievement.

A portion of the qualities which are considered as determinants of client fulfillment include: generally fulfillment, information satisfaction - distinction between data required and got, delight, programming fulfillment, and choice making satisfaction. In our unique circumstance, client fulfillment is a significant methods for estimating the degree of fulfillment of framework clients, i.e., employees of the college school while utilizing the framework during the time spent information section, information control, report generation, information recovery and arrangement to the necessary body (counting the administration, Ministry of Education, Education Bureaus, understudies, various divisions, coordination focuses). Some of client fulfillment attributes which are pertinent to the study are generally speaking fulfillment level, degree of reliance on the framework, expanded status of representatives, individual be nefits gained, affirmation of handiness of the framework[20]-[22].

Baroudi et al., (1986) recommend that if client fulfillment is translated as a mentality, the Theory of Reasoned Action (Fishbeinand Ajzen, 1975, refered to in DeLone and McLean, 1992) underpins the model that client fulfillment will impact expectations touse the framework and genuine use. It is normal that the level of client fulfillment can influence the measure of utilization of SIMS. In addition to this, since client fulfillment is an immediate forerunner of individual effect factors the previous influences the latter. Therefore, in view of these connections we set up the accompanying speculations in connection to client fulfillment develop.

H5b: SIMS client fulfillment will be emphatically identified with the utilization of SIMS.

H6: SIMS client fulfillment will be emphatically identified with individual effects of the SIMS.

The individual effect measurement is characterized by DeLone and McLean (1992) as "the impact of data on the conduct of the beneficiary". A portion of the attributes which are considered as determinants of individual effect include: information understanding, learning, exact understanding, data mindfulness, data review, issue recognizable proof, decision effectiveness, improved singular profitability, and errand execution. Those attributes which are most applicable to the study are execution related issues. According to Bokhari (2005), "The prime reason for bringing IS into an association is to improve individual decision-production execution as well as in general hierarchical productivity and adequacy. The normal gains in wording of organizational objectives through IS execution and appropriation are worried about the achievement of the framework". Accordingly, the impact on singular execution ought to in the end have some hierarchical effect. In this way, the conceivable hypotheses that can be constructed is the accompanying:

H7: The effect on singular execution will be identified with the authoritative effects of SIMS[23]

\section{RESULTS AND DISCUSSIONS}

A review instrument will be utilized to accumulate information to test the connections appeared in the exploration model. Essential clients of the framework at the college school will be overviewed with the end goal of requesting their perspectives and evaluation of the framework being utilized[24]-[25]. The objective populace incorporates all staff individuals from the Registrar Office and Finance Office, the school personnel and the top the executives of the college school. The complete number of respondents is required to be292. Three reciprocal techniques will be utilized for gathering essential information: poll, meet and direct perception of Student Information Management System and administrations. The inquiries are drawn from recently approved instruments and adjusted to the present investigation setting. Data on the instruments or measures is presented in Appendix A. The examination will utilize perceptual measures to catch information on IS achievement factors. Perceptual estimates are worthy measures in most study look into. A five-point Likert scale will be utilized to speak to the reactions of the subjects.

\section{CONCLUSION}

The discoveries of this work in progress study will show the significance of IS achievement factors in deciding the effectiveness of SIMS applications in the advanced education condition. This paper will make four significant commitments. First, it offers understanding of estimating the achievement of IS with regards to advanced education foundations of low pay nations, for example, Ethiopia Second, it demonstrates which variables can become prevailing in the accomplishment of a framework, particularly when it is created in-house. Third, the recognizable proof of accomplishment variables will help the top the board to concentrate on these elements and make the fundamental intercessions. 
Fourth, it will open an opportunity and exercises learned for further look into in the zone. In general, this will be both a hypothetical and down to earth commitment to the field of IS achievement when executed in HEIs; in particular HEI in low pay nations may profit by the exercises learned. Since this is even more a model structure study, separated of our future arrangement is to lead experimental research to approve the develops exhibited in the model.

\section{REFERENCES}

1. Vasanthi, S. \& Rabiyathul Basariya, S. 2019, "Influence of value analysis and cross training in industry", International Journal of Engineering and Advanced Technology, vol. 8, no. 6, pp. 1810-1811.

2. Velvizhi, R., Sri Gowtham, S. \& Jeya Priya, D. 2019, "Examination of early feedbacks for effective product retailing on E-commerce websites", International Journal of Engineering and Advanced Technology, vol. 8, no. 6 Special Issue 2, pp. 703-706.

3. Anuradha, C., Pothumani, S. \& Kavitha, R. 2019, "A novel method towards E-commerce", International Journal of Engineering and Advanced Technology, vol. 8, no. 6 Special Issue 2, pp. 535-538.

4. Thomas, J. \& Rabiyathul Basariya, S. 2019, "A study on the issues of financial ratio analysis", Indian Journal of Public Health Research and Development, vol. 10, no. 3, pp. 1079-1081.

5. Ramachandran, S. \& Rabiyathul Basariya, S. 2019, "Online marketing study on customer satisfaction and relationship", Indian Journal of Public Health Research and Development, vol. 10, no. 3, pp. 1072-1078.

6. Priya, R., Vinothini, G. \& Cor Jesu, C.D. 2019, "The mentor-protégé relationship for professional growth", Journal of Advanced Research in Dynamical and Control Systems, vol. 11, no. 9 Special Issue, pp. 1110-1119.

7. Jannifer Rani, N., Bina Pani, S. \& Nimisha, N.S. 2019, "A study on money back polices available in LIC", Journal of Advanced Research in Dynamical and Control Systems, vol. 11, no. 9 Special Issue, pp. 833-839.

8. Saillaja, V., Jhansi Rani, K. \& Catherine, R. 2019, "Global marketing management planning and organization", Journal of Advanced Research in Dynamical and Control Systems, vol. 11, no. 9 Special Issue, pp. 489-493.

9. Saillaja, V., Jhansi Rani, K. \& Catherine, R. 2019, "The new phase of marketing information system", Journal of Advanced Research in Dynamical and Control Systems, vol. 11, no. 9 Special Issue, pp. 482-488.

10. Thoufiqulla \& Raju, D.V. 2019, "Perception of indian investor towards investment in mutual funds with special reference to mip funds", Journal of Advanced Research in Dynamical and Control Systems, vol. 11, no. 5, pp. 177-183.

11. Jasmine, K.R.M. \& Basariya, S.R. 2018, "A study on the customers benefits on mutual funds", International Journal of Civil Engineering and Technology, vol. 9, no. 4, pp. 45-48.

12. Vasanthi, S. \& Basariya, S.R. 2019, "Pros and cons of on the job training versus off the job training", International Journal of Scientific and Technology Research, vol. 8, no. 10, pp. 671-674.

13. Pavithra, J. \& Ganesan, M. 2016, "A study on awareness and impact of micro-financial schemes", International Journal of Applied Business and Economic Research, vol. 14, no. 8, pp. 5449-5460.

14. Pavithra, J., Dilli Babu, P. \& Ambuli, T.V. 2014, "A study on budgetary control at Maruti Service Masters, Chennai", International Journal of Applied Business and Economic Research, vol. 12, no. 2, pp. 151-161.

15. Gunaraja, T.M. \& Venkatrama Raju, D. 2018, "Determining factors of organisational climate with reference to leadership styles", International Journal of Mechanical Engineering and Technology, vol. 9, no. 9, pp. 1327-1332.

16. Gunaraja, T.M. \& Venkatrama Raju, D. 2018, "The role of job satisfaction and training of employees in determining organisational climate of a selected industry", International Journal of Civil Engineering and Technology, vol. 9, no. 8, pp. 1266-1269.

17. Aarathy, T.S. \& Raju, D.V. 2018, "Performance appraisal and its effects on employees with respect to it sector in Chennai city", International Journal of Civil Engineering and Technology, vol. 9, no. 6, pp. 1535-1538.
18. Aarathy, T.S. \& Raju, D.V. 2018, "Employee perception towards performance appraisal system in IT sector", International Journal of Mechanical Engineering and Technology, vol. 9, no. 5, pp. 131-135.

19. Porselvi, W., Jublee, D. \& Sivanesan, G. 2018, "A study on factors influencing adoption of technology and innovation in banking industry, tamilnadu, India", International Journal of Mechanical Engineering and Technology, vol. 9 , no. 5, pp. 789-800.

20. Akessa, G.M. and Dhufera, A.G., 2015. Factors That Influences Students Academic Performance: A Case of Rift Valley University, Jimma, Ethiopia. Journal of Education and Practice, 6(22), pp.55-63.

21. Miller, G. and Shih, C.C., 1999. A faculty assessment of the academic rigor of on-and off-campus courses in agriculture. Journal of Agricultural Education, 40, pp.57-65.

22. Tsinidou, M., Gerogiannis, V. and Fitsilis, P., 2010. Evaluation of the factors that determine quality in higher education: an empirical study. Quality Assurance in education, 18(3), pp.227-244.

23. Farooq, M.S., Chaudhry, A.H., Shafiq, M. and Berhanu, G., 2011. Factors affecting students' quality of academic performance: a case of secondary school level. Journal of quality and technology management, 7(2), pp.1-14

24. Fitsilis, P., Gerogiannis, V. and Anthopoulos, L., 2014. Ontologies for software project management: a review. Journal of Software Engineering and Applications, 7(13), p.1096.

25. Adams, J.D. and Jaffe, A.B., 1996. Bounding the effects of R\&D: an investigation using matched establishment-firm data(No. w5544). National bureau of economic research.

\section{AUTHORS PROFILE}

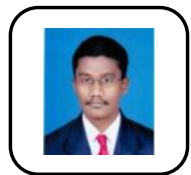

J.Kannan, Associate Professor, Department of Commerce and Economics, Bharath Institute of Higher Education and Research, Chennai , India.

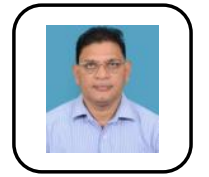

D. Venkatrama Raju,, Professor, Department of Commerce and Economics, Bharath Institute of Higher Education and Research, Chennai, India. 